\title{
Los académicos como agentes de cambio institucional: el caso del Instituto Tecnológico de Sonora, 2003-2018
}

\section{Academics as Agents of Institutional Change: The Case of the Instituto Tecnológico de Sonora, 2003-2018}

\author{
Gabriel Galindo Padilla* (iD https://orcid.org/0000-0002-2297-3773 \\ Juan Poom Medina** (iD https://orcid.org/0000-0002-1146-7381
}

\section{Resumen}

El objetivo de este artículo es analizar los cambios institucionales en el Instituto Tecnológico de Sonora entre 2003 y 20I8. La metodología empleada es el estudio de caso, además de fuentes primarias y entrevistas semiestructuradas; este método limita la generalización, pero permite profundidad. Los resultados demuestran la constitución de los académicos como agentes subversivos que provocan cambio institucional por estratificación conforme a la teoría del cambio institucional gradual, en contraste con algunos trabajos en el ámbito nacional que demuestran la incidencia de políticas públicas, gobiernos estatales y autoridades universitarias como agentes que acotan la autonomía, producen gobiernos menos democráticos y menos legítimos, y reducen el poder de los académicos en la universidad. Se concluye que éstos pueden influir en el rumbo de las universidades y tienen capacidades para producir cambios significativos en la organización utilizando sus propios recursos y estrategias aun en condiciones de restricción a su capacidad de agencia.

Palabras clave: académicos; autonomía; cambio institucional; educación superior; estudio de caso; gobierno universitario; políticas públicas; universidad pública.

\section{Abstract}

The objective of this article is to analyze the institutional change in the Instituto Tecnológico de Sonora from 2003 to 2018 . The study is carried out following the case study method, using primary sources and semi-structured interviews; this method limits generalization but allows depth. The results demonstrate the constitution of academics as subversive agents that cause institutional change by stratification according to the theory of gradual institutional change. Results are compared to some works at the national level that demonstrate the incidence of public policies, state governments and university authorities as agents which limit autonomy, produce less democratic and legitimate governments, and reduce the power of academics in the university. It is concluded that the academics can influence the course of the universities and have capacities to produce significant changes in the organization using their own resources and strategies even in conditions of restriction to their agency capacity.

Keywords: academics; autonomy; case study; higher education; institutional change; public policies; public university; university government.

Cómo citar: Galindo Padilla, G., y Poom Medina, J. (2020). Los académicos como agentes de cambio institucional: el caso del Instituto Tecnológico de Sonora, 2003-20 I8. región y sociedad, 32, el 267. doi: I0.22 I98/rys2020/32/I 267

* Autor para correspondencia. Instituto Tecnológico de Sonora, Dirección de Ciencias Sociales y Humanidades. 5 de Febrero Núm. 818 Sur, C. P. 85000. Ciudad Obregón, Sonora, México. Correo electrónico: gabriel.galindo@itson.edu.mx

** El Colegio de Sonora. Centro de Estudios en Gobierno y Asuntos Públicos. Ave. Obregón Núm. 54 Col. Centro, C. P. 83000. Hermosillo, Sonora, México. Correo electrónico: jpoom@colson.edu.mx

Recibido: 7 de noviembre de 2019

Aceptado: 27 de abril de 2020

Liberado: 8 de junio de 2020 


\section{Introducción}

El Instituto Tecnológico de Sonora (ITSON), de acuerdo con el artículo 2 de su ley orgánica, "es un organismo público descentralizado, de carácter universitario, con personalidad jurídica y patrimonio propio, autónomo” (ITSON, 2019). Y conforme al artículo 6 de la misma ley, tiene un Consejo Directivo como máxima autoridad (ITSON, 2011). Presta servicios en el sur del estado de Sonora con seis campus en cuatro municipios: Cajeme, Navojoa, Guaymas y Empalme. La matrícula asciende a más de 16 mil estudiantes en 24 programas de grado y 16 de posgrado, incluidos 3 doctorados (ITSON, 2018). Es la segunda universidad en tamaño e importancia en Sonora.

En 2003 el H. Congreso del Estado de Sonora reformó la ley orgánica de la universidad y puso fin a 24 años de rectoría de Oscar Russo Vogel, lo cual propició un cambio político en la universidad que activó la participación de distintos agentes externos e internos. En este artículo se estudian los cambios institucionales acontecidos en el ITSON desde esa reforma, los agentes involucrados y los resultados de la acción de éstos sobre la institución.

La pregunta que guía este trabajo es: ¿cuál es el papel de los académicos en el cambio institucional del ITSON en el periodo 2003-2018? La respuesta que se somete a comprobación es que los académicos se trasformaron en agentes de cambio actuando dentro de los márgenes de las reglas institucionales y explotando sus ambigüedades para generar ajustes en las normas, que incrementaron su poder y produjeron un cambio institucional gradual en el ITSON.

El principal hallazgo de este estudio señala que los académicos del ITSON influyeron en el cambio de rumbo de la universidad y se constituyeron en agentes que produjeron trasformaciones significativas en la institución, abonando a la construcción de una universidad más democrática.

El artículo se organiza en seis apartados después de la introducción: antecedentes, metodología basada en el estudio de caso, con fuentes primarias y entrevistas semiestructuradas, enfoque teórico centrado en el institucionalismo sobre cambio gradual, discusión sobre agentes de cambio en el contexto universitario, constitución y rol de los académicos del ITSON y su contribución a la trasformación institucional en la universidad y el apartado de conclusiones.

\section{Antecedentes}

Los antecedentes del ITSON datan del 11 de julio de 1955 al constituirse en Ciudad Obregón, Sonora, el Instituto de Estudios Superiores Justo Sierra, organismo privado de educación media superior (ITSON, 2019). Inicia actividades el 21 de septiembre de 1955. En 1956 cambia su nombre a Instituto Tecnológico del Noroeste y transita de institución privada a pública el 23 de mayo de 1962 con la ley 20 que crea el Instituto Tecnológico de Sonora. Obtiene categoría universitaria cuando el Congreso local publica la ley 3 el 17 de octubre de 1964, y logra su autonomía el 5 de octubre de 1976 con la publicación de la ley 2 gra- 
cias a las gestiones de Eduardo Estrella Acedo, primer rector del ITSON (Vargas Becerril, Aguilera Guerrero y Anaya Mexía, 2005).

Al término del periodo de Estrella Acedo le sucede en la rectoría Oscar Russo Vogel, quien es designado para un primer periodo en 1979 pero permanece en el cargo durante seis periodos, hasta 2003, es decir, 24 años. La ley orgánica no estableció límite al número de reelecciones: “El rector será representante legal del Instituto, Presidente del Consejo Directivo y ejecutor de sus acuerdos. Durará en sus funciones cuatro años y podrá ser reelecto" (Congreso del Estado de Sonora, 1976).

A finales de 2003, el Congreso local aprobó una reforma al artículo 15 de la ley orgánica para limitar la reelección a un solo periodo. Se señala que "El Rector será representante legal del Instituto, Presidente del Consejo Directivo y ejecutor de sus acuerdos. Durará en sus funciones cuatro años y podrá ser reelecto por un periodo" (Congreso del Estado de Sonora, 2003). Además, el artículo cuarto transitorio de la misma ley impide una nueva postulación del rector en funciones, lo que cerró las posibilidades de reelección de Russo Vogel al frente del ITSON.

Así, el largo periodo de Russo Vogel llegó a su fin y el Consejo Directivo designó a Gonzalo Rodríguez Villanueva como rector de 2002 a 2007 y fue reelecto por un periodo, de 2007 a 2011. A partir de ese momento ocurrieron cambios en todas las áreas de la institución y de los cuales este artículo se ocupa.

\section{Metodología}

La metodología empleada es el estudio de caso, con abordaje cualitativo. Se construyó una base de datos con 172 actas de sesiones realizadas en el periodo de 1999 a 2018, para analizar las decisiones del Consejo Directivo mediante la estadística descriptiva.

Los consejos directivos toman decisiones, muchas de ellas eventuales y efímeras en la vida universitaria, pero, con frecuencia, también decisiones importantes que permiten construir análisis e identificar variaciones históricas. Son las que se privilegian en el análisis de la base de datos. Se incluyen testimonios obtenidos de catorce entrevistas semiestructuradas a informantes clave (tres ex rectores, tres exsecretarios generales del sindicato único de trabajadores, dos funcionarios no académicos, académicos y exalumnos con representación en el Consejo Directivo). Se citan sus opiniones a partir del ordenamiento en función de la fecha de recolección (de enero a marzo de 2019). Así mismo, cada entrevista se ordenó de manera aleatoria para identificar al informante con un número para proteger su identidad.

Con autorización de los entrevistados, conforme a un instructivo de consentimiento informado, las entrevistas se grabaron por medio de aplicación móvil (grabadora de voz fácil) en formato wav. Se trascribieron a Word haciendo uso

del software Express Scribe, se codificaron y analizaron con el programa Nvivo 12 de acuerdo con categorías de análisis ya establecidas. 
Por último, se recurrió a la revisión de acuerdos legislativos, a los diarios de debates en el Congreso local y al análisis hemerográfico en tres periódicos de influencia estatal y/o regional (El imparcial, Tribuna del Yaqui y Diario del Yaqui) para la descripción de los puntos de inflexión históricos del ITSON en el periodo que se estudia.

\section{Elementos teóricos}

Las universidades como instituciones y organizaciones

Las universidades han acompañado el desarrollo de la sociedad. Aunque sus antecedentes históricos pueden rastrearse antes de la era moderna, su carta de naturalización se ubica en el siglo XIX (Altbach, 1991; Brunner, 2014; Casanova Cardiel, 2015). La universidad es una institución de interés público y objeto de política pública relevante (Valenti Nigrini y Castillo Alemán, 1997) al formar a las élites y cuadros medios de profesionales. Es clave en la reproducción de comunidades científicas y disciplinares, forma el personal docente de las instituciones de educación media y superior y atiende en buena medida los problemas nacionales.

La universidad pública tradicionalmente ha cumplido funciones de docencia, investigación, creación y extensión (Pérez Muñoz y Castaño Calle, 2016). Desde su origen ha experimentado importantes trasformaciones que se han acelerado con el advenimiento de la globalización. En este contexto, los Estados han demandado de ésta una mayor funcionalidad hacia el aparato productivo, sometiendo a la universidad al profundo proceso de modificación y de reconceptualización en el que se encuentra en la actualidad.

Las trasformaciones de las universidades se han abordado a partir de diferentes enfoques, en especial el organizacional, que pone atención en la innovación; los estudios comparados con prevalencia de estudios históricos y de análisis de las reformas que surgen del Estado; y el neoinstitucionalismo, que se ocupa de explicar los procesos de estabilidad y de cambio en un sentido amplio (Cortés Vargas, 2009). Este estudio retoma la vertiente neoinstitucionalista para examinar las trasformaciones del ITSON, sobre todo por el tipo de caso que representa en el que el cambio gradual es una de las características principales de su modificación.

La teoría del cambio institucional y la universidad pública

Las instituciones no sólo nacen y permanecen, también cambian. Estabilidad y cambio se encuentran íntimamente ligados y el nuevo institucionalismo se ha esforzado en ocuparse de estos conceptos. Sin embargo, los diversos institucionalismos se han habilitado para explicar la estabilidad (Vergara, 2010, p. 43 ) más que el cambio institucional y esto se ha convertido en uno de sus puntos débiles (Gómez, 2015, p. 392). El cambio institucional es concebido como 
“un proceso de diferenciación estructural creciente que presupone no sólo la reforma o ajuste de normas, reglas y valores institucionalizados, sino también la incorporación de nuevos actores, intereses y conflictos en las distintas arenas, esferas o áreas del desempeño institucional" (Acosta Silva, 2002, p. 20). El cambio institucional puede tener causas internas o externas, con efecto significativo en los elementos organizacionales (estructura, personas y decisiones) y refleja una redistribución del poder en las organizaciones.

Desde el institucionalismo histórico ha emergido la teoría del cambio institucional gradual (TCIG) propuesta por Mahoney y Thelen (2010) cuyo atractivo es su visión gradual del cambio y su capacidad para dialogar con distintas corrientes del cambio institucional (Gómez, 2015). La tesis central de este enfoque es que las reglas institucionales están sujetas a diferentes interpretaciones y niveles de cumplimiento, por lo que presentan ambigüedades que los agentes interesados explotan para tener acceso a mayores beneficios de los que disponen en el estado institucional vigente. De esa forma, el cambio gradual se sostiene en tres elementos básicos: ambigüedad de las reglas, agencia y poder, y sitúa la agencia en el centro del análisis (Mahoney y Thelen, 2010).

Las reglas tienen una naturaleza ambigua aun siendo codificadas de manera formal. Los actores con intereses divergentes luchan por su interpretación, aplicación y cumplimiento, porque están ligadas a la asignación de recursos. La ambigüedad de las reglas se debe 1) a que no son lo suficientemente precisas para cubrir todas las situaciones posibles de la realidad; 2) a los límites cognitivos de los actores, que no pueden anticipar todas las posibles situaciones futuras en las que las reglas se implementarán; 3) a que las instituciones están integradas por supuestos que son sólo implícitos, que pueden variar a lo largo del tiempo; y 4) las reglas no sólo se diseñan, también deben interpretarse y aplicarse con frecuencia por quienes no participaron en su diseño, lo que abre un espacio para cambios en su interpretación y aplicación (Mahoney y Thelen, 2010, pp. 10-14).

Tabla 1. Síntesis gráfica de la TCIG

\begin{tabular}{|c|c|c|c|}
\hline \multicolumn{4}{|c|}{ Fuentes contextuales e institucionales de agentes de cambio } \\
\hline & & \multicolumn{2}{|c|}{ Características de la institución elegida } \\
\hline & & $\begin{array}{c}\text { Bajo nivel de } \\
\text { discrecionalidad } \\
\text { en interpretación / } \\
\text { cumplimiento }\end{array}$ & $\begin{array}{c}\text { Alto nivel de } \\
\text { discrecionalidad } \\
\text { en interpretación / } \\
\text { cumplimiento }\end{array}$ \\
\hline \multirow{2}{*}{$\begin{array}{c}\text { Características } \\
\text { del contexto } \\
\text { político }\end{array}$} & $\begin{array}{c}\text { Fuertes } \\
\text { posibilidades de veto }\end{array}$ & $\begin{array}{l}\text { Subversivos } \\
\text { (estratificación) }\end{array}$ & $\begin{array}{l}\text { Parásitos simbiontes } \\
\text { (desviación) }\end{array}$ \\
\hline & $\begin{array}{c}\text { Débiles } \\
\text { posibilidades de veto }\end{array}$ & $\begin{array}{l}\text { Insurreccionarios } \\
\text { (desplazamiento) }\end{array}$ & $\begin{array}{l}\text { Oportunistas } \\
\text { (conversión) }\end{array}$ \\
\hline
\end{tabular}

Fuente: Mahoney y Thelen (2010, p. 28). Traducción propia. 
En este caso, el motor del cambio es la distribución del poder en las instituciones. El espacio para el cambio son las ambigüedades entre la regla y su interpretación o entre la regla y su implementación (Gómez, 2015). Si el significado o la aplicación de una norma es ambiguo, el interés de un actor en la continuidad institucional también lo será. Si significado y aplicación cambian, también pueden variar las preferencias de los actores, lo cual obliga a pensar en nuevas categorías de los actores en función de sus estrategias. Por otra parte, de acuerdo con Mahoney y Thelen (2010), agencia, ambigüedad y poder institucional producen cuatro formas de cambio institucional gradual y cuatro tipos de agentes de cambio, según el contexto político y las características institucionales (pp. 14-31). Una vista esquemática de esta teoría se observa en la tabla 1.

La primera forma de cambio gradual es el desplazamiento, en el cual se remplazan las reglas por otras nuevas. Esa sustitución puede suceder de forma abrupta y propiciar una trasformación radical, como explican otras teorías institucionales. El desplazamiento también puede ser lento cuando se introducen nuevas reglas que, en vez de complementar, compiten con las antiguas; los agentes perdedores incitan a la deserción de las nuevas reglas, lo que da lugar a un desplazamiento gradual.

El desplazamiento sucede en un contexto político de débiles posibilidades de veto y baja discrecionalidad en las reglas. Los agentes insurreccionales protagonizan este cambio; rechazan el statu quo institucional y buscan eliminar las reglas existentes en favor de unas nuevas. Si el desplazamiento es gradual, se debe a que no cuentan con las condiciones para hacer que las cosas se modifiquen tan rápido como quisieran.

La estratificación, segunda forma de cambio gradual, ocurre cuando nuevas reglas se incorporan a las existentes en forma de enmiendas, revisiones o adiciones, alterando la lógica de la institución. Los retadores institucionales no tienen la capacidad de cambiar las reglas originales y optan por trabajar dentro del sistema agregando nuevas normas sobre las antiguas. Los defensores del sistema no pueden impedir la introducción de modificaciones, y cada nuevo elemento añade pequeñas variaciones que, acumuladas, producen una gran trasformación en el largo plazo.

Este tipo de cambio institucional tiene lugar en un contexto político de fuertes posibilidades de veto y bajo nivel de discrecionalidad institucional. Los agentes subversivos trabajan dentro del sistema promoviendo nuevas reglas en los límites de las antiguas y, en consecuencia, provocan estratificación.

La tercera forma de cambio gradual, la desviación, sobreviene cuando las reglas permanecen iguales, pero su efecto varía como resultado de modificaciones en las condiciones medioambientales. Al no responder a cambios ambientales, una deliberada o negligente falta de acción de los agentes puede causar un impacto trascendente en la institución. Fuertes posibilidades de veto en lo político y alta discrecionalidad en las reglas son el contexto de la desviación. Agentes simbiontes, en modalidad parásito, actúan en escenarios de brechas en el cumplimiento de las reglas, y eso genera desviación. 
La conversión, cuarta forma de cambio gradual, se produce cuando hay una modificación en la interpretación o en la ejecución de las reglas y se contrapone al sentido en su diseño. Esto es llevado a cabo por agentes que explotan las ambigüedades inherentes de las instituciones.

Un contexto político de débiles posibilidades de veto y alto nivel de discrecionalidad en el cumplimiento de las reglas es el espacio donde se da la conversión. Agentes oportunistas, con preferencias ambiguas sobre la continuidad institucional, pueden explotar cualquier posibilidad que favorezca sus fines.

En resumen, la TCIG explica que las instituciones permanecen porque están en constante cambio y es una herramienta útil para estudios en el contexto latinoamericano (Gómez, 2015). En este artículo se pone a prueba su utilidad para el estudio del cambio en las universidades al analizar el caso del ITSON. Además, se sigue la idea de Acosta (2000, p. 21), según la cual las universidades son instituciones cargadas de poder entre las fuerzas y élites internas.

Por último, guía este estudio la idea de que la permanencia y el éxito de las instituciones están basados en formas de cambio gradual, frecuente y endógeno, producto de la revisión, suplementación e interpretación de las reglas por agentes que explotan los recursos y las ambigüedades de las instituciones (Mahoney y Thelen, 2010).

\section{Agentes y cambio institucional en las universidades públicas mexicanas}

A partir de la década de 1990, denominada etapa de la modernización (Kent, 2009; Rodríguez y Casanova, 2005; Mendoza, 1992), las universidades públicas mexicanas experimentaron modificaciones profundas. Los estudios sobre cambio institucional detectaron durante esa época tres diferentes agentes de cambio: las políticas públicas, los gobiernos estatales y las autoridades universitarias, y presentaron a los académicos como los grandes desplazados del poder y de su agencia. ${ }^{1}$

Las políticas públicas

Las políticas federales transitaron de un financiamiento universitario benigno y negligente buscando legitimidad en los años setenta a uno, a partir de los noventa, condicionado a las mejoras en la calidad, en la trasparencia y en la competitividad de las universidades (Fuentes Molinar, 1991).

Estos ajustes no se sustentaron en reformas legales, sino en la autoridad y capacidad financiera del Estado para el establecimiento de políticas (Kent, 2009; Vries y Álvarez Mendiola, 2005) mediante las cuales las universidades

1 "La agencia se refiere no a las intenciones que la gente tiene en hacer las cosas, sí a su capacidad de hacer cosas" (Giddens, 2006, p. 9). 
públicas, comportándose como campo organizacional, incorporaron las nuevas políticas a sus rutinas por un proceso de isomorfismo coercitivo. ${ }^{2}$

Destaca el Programa Integral de Fortalecimiento Institucional (PIFI), creado en 2001, que permanece y ha evolucionado. El programa introduce una serie de indicadores integrados por una diversidad de procesos universitarios: evaluación, acreditación, planeación participativa, rendición de cuentas y financiamiento (Comas, Fresán, Buendía y Gómez, 2014), buscando impactar a mediano y largo plazo en la gestión, capacidad y competitividad académica de las instituciones.

Tales políticas han producido un doble efecto en las universidades: por un lado, la intervención del Estado ayudó a las instituciones de educación superior (IES) a amortiguar los problemas que habían venido experimentando, como la ineficiencia, la burocratización y la politización, lo que permitió recuperar reconocimiento y prestigio social. Así mismo no estuvieron exentas de críticas por su orientación, limitaciones y efectos producidos en las IES.

Entre los efectos negativos significativos que se les atribuyen está una visión homogeneizada sobre el quehacer de las universidades (Porter Galetar, 2004), ignorando y afectando su (deseable) diversidad, simulación institucional, socavamiento de la autoridad institucional y acotamiento de la autonomía al colocar en un segundo plano a las autoridades institucionales (Porter Galetar, 2004; López Zárate, 2012).

En los años recientes algunos autores (Álvarez Mendiola y Vries, 2014; López Zárate, 2012; Rodríguez Gómez, 2015) han señalado que estas políticas parecen agotadas; sin embargo, éstas se mantienen y evolucionan de forma incremental, de tal suerte que en la actualidad son el principal agente de cambio institucional y han cubierto todo el espectro universitario.

\section{Los gobiernos estatales}

Otro agente de cambio institucional de las universidades públicas mexicanas han sido los gobiernos estatales. Aunque la mayoría de las universidades de México dependen jurídica, administrativa y financieramente (al menos de forma parcial) de los gobiernos locales, éstos no demandan políticas públicas para ellas. Esto es competencia casi exclusiva de la federación (Rodríguez Gómez, 2009).

El poder de los gobiernos locales en las IES se ejerce en muchos sentidos y presenta marcadas diferencias en función del subsistema de que se trate. Para las universidades públicas estatales de apoyo solidario, institutos tecnológicos descentralizados, universidades tecnológicas y escuelas normales, el poder del gobierno local es pleno al tener participación directa en todos los ámbitos de su vida institucional, mientras que el poder local en las universidades públicas estatales autónomas (UPES) se encuentra más delimitado, puesto que el gobierno local no puede proponer políticas para ellas debido a que el estatus de autono-

2 El isomorfismo coercitivo es producto de presiones desplegadas sobre organizaciones desde otras de las cuales dependen (DiMaggio y Powell, 1999). 
mía de las universidades lo restringe, por lo que ordinariamente se encuentra centrada en la gestión financiera y en la atención a tipos de agendas puntuales.

Eventualmente y de forma individualizada, el gobierno local decide ejercer su poder de veto modificando su ley orgánica cuando las UPES se encuentran en crisis de gobernabilidad, lo que provoca un cambio trascendente que genera múltiples efectos a veces perniciosos para la autonomía. La participación del gobierno local como agente en las universidades en conflicto centra su intervención por lo general en favor de quienes encabezan un proyecto isomorfo a las políticas públicas, sean las autoridades universitarias o un grupo alternativo que conforme una nueva élite de poder y pueda conducir la institución hacia una reforma deseable.

Un ejemplo que ilustra la acción eventual pero trascendente del gobierno local como agente de cambio es el caso de la Universidad de Sonora en el año 1991 cuando se reformó la ley orgánica y con ello el gobierno universitario pasó de Consejo Universitario a Junta Universitaria, lo que trajo consigo otros cambios institucionales importantes en lo político, organizativo, administrativo, normativo y académico (Acosta Silva, 2000; Durand Villalobos, 2006). Otro ejemplo es el mismo ITSON con la reforma del artículo 15 de su ley orgánica.

\section{Las autoridades universitarias}

Las autoridades universitarias también conducen cambios institucionales al contar con la autoridad para orientar las acciones de la universidad a través de la visión que proponen en los planes de desarrollo institucional o en los documentos internos de trabajo que reflejan el camino a seguir.

Tres casos ayudan a ilustrar esta capacidad de agencia. Los dos primeros se ubican en la etapa temprana de la modernización educativa y el tercero se ubica en la introducción de la planeación estratégica. Los resultados en cada caso resultan diferentes.

El primero de ellos es la Universidad de Guadalajara (UdeG). Ahí se experimentaba una situación de verticalidad, burocracia, aumento descontrolado de la matrícula, vocación profesionalizante, desvinculación entre academia e investigación, insuficiente apoyo a la investigación y al posgrado, oferta académica reducida y concentrada en profesiones tradicionales, falta de homologación salarial además de un acceso al poder basado en clientelismo y patrimonialismo (Almeida López, 2012).

En el rectorado de Raúl Padilla López en 1989 inicia una reforma institucional que culmina con la expedición de la ley orgánica de 1993 que confiere autonomía a la UdeG y faculta al Consejo General Universitario como órgano de gobierno para designar rector. A este cambio en el gobierno institucional lo acompañaron cambios académicos, políticos, organizacionales y normativos de largo alcance que moldearon la universidad actual (Acosta Silva, 2000).

El segundo caso es la Benemérita Universidad Autónoma de Puebla (BUAP). Del modelo populista que había operado por veinte años (1972-1990), caduco ante las políticas modernizadoras (Ornelas, 1998), se desprende una corriente modernista, isomorfa a las nuevas políticas, que pone el desarrollo académico 
como centro de su discurso y alcanza la rectoría con José Marún Doger Corte (1990-1993 y 1993-1997).

El proyecto modernista impulsó un cambio institucional con los siguientes resultados: en lo académico hubo políticas de ingreso, permanencia y egreso más estrictas, diversificación de la oferta académica y fortalecimiento de la investigación y de los cuerpos académicos. En lo político y el gobierno, hubo cambios en la ley orgánica y en la designación de rector; en lo organizativo se crearon los subsistemas de docencia, investigación, posgrado y extensión de la cultura (Acosta Silva, 2000; Ornelas, 1998).

El tercer caso se refiere a la Universidad Autónoma de Nayarit. En 2003, por iniciativa de la universidad, se reforma su ley orgánica y el siguiente año el Consejo General Universitario aprueba su estatuto de gobierno. La intención era transitar de un modelo de organización por facultades a uno departamental y crear órganos de gestión académica que debían ser cuerpos colegiados centrales en el cambio institucional hacia la calidad académica, pero el alcance de la reforma fue limitado.

La distribución de los recursos y la elección de autoridades no tuvieron cambios sustanciales, por lo que la reforma se dio sólo en los aspectos organizacionales y administrativos. La mayor trasformación institucional se observa en el paso de un orden permisivo a uno normativo, en el que la discrecionalidad fue deslegitimada (Arias Guzmán, Ceja Mendoza, Ramos Carrillo, Ríos Colín, 2011).

Este último caso es un ejemplo de cambio institucional fallido, debido a que el agente principal no logró integrar una coalición ganadora para implementar las modificaciones que se propusieron, en contraste con los casos de la UdeG y de la BUAP, donde el grupo de gobierno tuvo la capacidad de conducir cambios institucionales profundos y exitosos.

La situación de los académicos

En contraste con lo expuesto en el apartado anterior, la posición de los académicos resulta dramática considerando que a principios del siglo XX alumnos y profesores son animadores de la Reforma de Córdoba, que inspiró a las universidades en América Latina para conquistar autonomía y cogobierno (Kandel, 2010) y que, siendo éstos el principal activo de la universidad, en la actualidad son los grandes damnificados de la etapa de la modernización, que ha traído consigo una trasformación significativa de sus condiciones de trabajo.

El discurso dominante ha puesto en crisis el concepto de mérito asociado con el trabajo académico. Dicho concepto se ha relacionado con la creación y recreación del conocimiento y con la formación de educandos, y ha sido sustituido parcialmente por la obtención de recursos externos para investigación, generación de patentes, venta de trabajo, servicios académicos y colocación de egresados en el mercado laboral (Ordorika Sacristán, 2004).

La concepción del mérito es importante pues está ligado a la identidad, pero también se refleja en el salario y los incentivos. El pago por méritos es extendido a escala internacional pero no supera $5 \%$ del ingreso total de los académicos, mientras que en México representa un alto porcentaje del salario percibido 
(Durand Villalobos, 2006). Por tanto, es elemento clave de una política de contención salarial (Álvarez Mendiola y Vries, 2014; Ordorika Sacristán, 2004).

El pago por méritos ha trastocado las características del trabajo académico. El llamado ethos académico ha sido puesto en crisis: se ha desvirtuado la función principal de la evaluación porque su contribución al mejoramiento docente y al aprendizaje de los alumnos (Rueda Beltrán y Diego Correa, 2012) ha diluido las finalidades sustantivas de la docencia en favor de una ganancia monetaria y ha convertido al académico en un burócrata del conocimiento (Ibarra Colado y Porter Galetar, 2007); ha generado una tendencia credencialista orientada por el dinero, el estatus y la sobrevivencia (Gil Antón, 2013) y ha fortalecido el individualismo y la meritocracia en detrimento de la colegialidad voluntaria y el compromiso intelectual (Silva Montes y Castro Valles, 2014).

Las políticas modernizadoras y el pago por méritos también han acarreado efectos negativos en el ejercicio de la ciudadanía y de la participación de los académicos en la universidad. Los ha distanciado de los asuntos colectivos y de la conducción y gobierno de la universidad (López Zárate, 2012; Suárez Zozaya y Muñoz García, 2004).

Estas políticas han convertido a los académicos en espectadores y rehenes, antes que actores de la agenda de políticas en la educación superior (Gil Antón, 2000), sin peso ni influencia en las decisiones institucionales. Son desplazados por las autoridades universitarias, a quienes perciben autocráticas (Galaz Fontes y Viloria Hernández, 2004), de donde se desprende que el académico ejerce una profesión subordinada, con poca influencia en la designación de funcionarios, la definición presupuestal y en general con todo lo que es relevante a su trabajo, a excepción de la investigación (Galaz Fontes y Viloria Hernández, 2014).

Se puede concluir que las políticas de educación modernizadoras, y en particular el sistema de pago por méritos, ha provocado desmovilización (Álvarez Mendiola y Vries, 2014) y en general una menor participación institucional de los académicos (Galaz Fontes y Gil Antón, 2013).

Ante este panorama, el cambio institucional del ITSON ofrece nuevas alternativas, que pasan por la comprensión de procesos que expliquen la capacidad de agencia de los académicos, aun con las condiciones descritas en los apartados anteriores.

\section{Discusión: los académicos ITSON como agentes de cambio institucional}

La estrategia de los académicos ITSON para colocar agenda

Una fuente importante para el cambio radica en el cumplimiento de las reglas debido a su naturaleza disputada, pero sobre todo por el margen que existe en su interpretación e implementación. En el contexto del ITSON, una vez cerrado el largo periodo de rector de Russo Vogel por el cambio en el artículo 15 de la ley orgánica en 2003, los académicos encontraron condiciones para desarrollar capacidad de agencia a nivel institucional. 
En el ITSON la creación, la enmienda, la revisión y la adición de normas están determinadas por el Consejo Directivo, órgano colegiado principal previsto en la ley orgánica, integrado por el rector, dos vicerrectores, ocho directores de funciones académicas, dieciséis representantes de los alumnos (uno por cada mil alumnos o fracción), otros dieciséis miembros del personal académico titular (uno por cada representante de los alumnos), un representante de los egresados, un representante del patronato, un representante del personal no académico y el secretario del Consejo, que es el secretario de la Rectoría. En la actualidad suman 47 miembros con derecho a voz y voto. Es importante puntualizar que representantes de académicos, alumnos, personal no académico y egresados son designados vía auscultación a los sectores correspondientes.

El artículo 24 del "Reglamento para el funcionamiento interno del Consejo Directivo" (RFICD) establece que el orden del día es aprobado por el Pleno al inicio de cada sesión. Éste fue uno de los espacios de ambigüedad en las reglas donde los académicos, buscando irrumpir con mayor participación en las decisiones colegiadas, colocaron agenda en las sesiones del Consejo, al proponer y aprobar por mayoría simple la inclusión de agenda propia, adicional a la propuesta por la autoridad, quien la había establecido siempre.

La agenda son los temas que se colocan en la atención del gobierno por la acción de agentes políticos que tienen la capacidad de impulsarlas ejerciendo sus recursos, facultades y poder (Casar y Maldonado, 2008, p. 10), por lo que puede concluirse, siguiendo a Przeworski (2005), que quien pone la agenda tiene poder. En este sentido, en el ITSON, a partir de 2007, las autoridades empezaron a compartir la decisión de colocar agenda.

Aquí se analiza la agenda no ordinaria, que es la que no está dispuesta por la normatividad como obligatoria (agenda obligatoria son los informes de comisiones, financieros, de actividades trimestrales del gobierno institucional y de ampliación presupuestal) y que evidencia los intereses que los distintos agentes o sectores de representación impulsan para provocar cambios que les son favorables.

En 2007 el sindicato de trabajadores, en la coyuntura de una revitalización interna, logró colocar temas de su interés, con lo cual mostró el camino para que a partir de 2008 los académicos pudieran convertirse en asiduos colocadores de agenda en el Consejo, a menudo en alianza con los representantes de los alumnos. Así, poco a poco fueron provocando un cambio institucional.

En la tabla 2 se presenta la agenda colocada por las distintas representaciones en el Consejo en las últimas cuatro administraciones de Rectoría. Se observa que en las sucesivas administraciones de Russo Vogel (1979-2003), ilustrada en este estudio sólo por sus últimos cinco años (1999-2003), la colocación de agenda era exclusiva de la autoridad. De la misma manera, sólo a partir del segundo periodo de Gonzalo Rodríguez (2002-2007 y 2007-2011) y durante las administraciones de Roberto Cruz (2012-2016) y Javier Vales (2016-2020), la agenda colocada por los diferentes sectores es frecuente: predominan los sectores de la autoridad y académicos. 
Tabla 2. Agenda colocada por sectores del Consejo Directivo, 1999-2018

\begin{tabular}{|c|c|c|c|c|c|c|c|c|}
\hline \multirow[b]{2}{*}{ Año } & \multirow[b]{2}{*}{ Sesiones } & \multicolumn{7}{|c|}{ Sesiones en que los agentes colocaron agenda no ordinaria en el Consejo Directivo } \\
\hline & & Autoridades & Académicos & $\begin{array}{c}\text { No } \\
\text { académicos }\end{array}$ & Alumnos & Patronato & Egresados & Sindicato \\
\hline \multicolumn{9}{|c|}{ Oscar Russo } \\
\hline 1999 & 8 & 8 & & & & & & \\
\hline 2000 & 6 & 4 & & & & & & \\
\hline 2001 & 5 & 2 & & & & & & \\
\hline 2002 & 5 & 4 & & & & & & \\
\hline 2003 & 9 & 5 & & & & & & \\
\hline \multicolumn{9}{|c|}{ Gonzalo Rodríguez } \\
\hline 2004 & 7 & 5 & & & & & & \\
\hline 2005 & 8 & 4 & & & & & & \\
\hline 2006 & 5 & 3 & & & & & & \\
\hline 2007 & 9 & 4 & 1 & 1 & & & & 5 \\
\hline 2008 & 7 & 4 & 3 & 2 & 2 & & & 1 \\
\hline 2009 & 9 & 6 & 6 & & & & & 2 \\
\hline 2010 & 9 & 7 & 8 & & 1 & & & \\
\hline 2011 & 17 & 13 & 7 & & & & & \\
\hline \multicolumn{9}{|c|}{ Roberto Cruz } \\
\hline 2012 & 13 & 11 & 4 & & 1 & & & \\
\hline 2013 & 9 & 6 & 1 & & 1 & & & \\
\hline 2014 & 9 & 7 & 2 & & & & & \\
\hline 2015 & 7 & 5 & 2 & & 2 & & & \\
\hline \multicolumn{9}{|c|}{ Javier Vales } \\
\hline 2016 & 12 & 9 & 4 & & 2 & & & \\
\hline 2017 & 13 & 11 & 1 & & & & & \\
\hline 2018 & 7 & 5 & 1 & & & & & \\
\hline
\end{tabular}

Fuente: elaboración propia con información de actas del Consejo Directivo, 1999-2018.

En la tabla 3 se presenta la competencia y la composición del Consejo para el mismo periodo de años de la tabla 2. Para ser representante de los académicos, de los trabajadores no académicos, de los alumnos y de los egresados se requiere competencia y opinión favorable conforme al sector de representación. Las autoridades y el presidente del patronato ocupan posiciones en el Consejo conforme al puesto que desempeñan.

Lo primero que se observa en la tabla 3 es que ha existido competencia por la representación de manera regular, a excepción del año 2017 para el caso de 
los académicos; esto se explica por la transición en el ejercicio del poder desde la Rectoría, cuando los académicos afines a la administración saliente dejaron de ocupar espacios, lo que produjo déficit de representación académica.

Si esta fuerza no participa [...] entonces hay una, hay una apatía muy fuerte, los representantes académicos y eso hace que el Consejo anterior, el Consejo 2017-2018 haya dejado 7 lugares vacantes de profes. (Informante 6)

Al contrastar las tablas 2 y 3 destaca otra relevancia. Desde el año 1999 los sectores de representación de académicos, alumnos y no académicos ya

Tabla 3. Candidatos y representantes por sector en el Consejo Directivo

\begin{tabular}{|c|c|c|c|c|c|c|c|c|c|c|}
\hline \multirow{3}{*}{ Año } & \multicolumn{10}{|c|}{ Tipo de representante } \\
\hline & \multicolumn{2}{|c|}{ Académico } & \multicolumn{2}{|c|}{ Administrativo } & \multicolumn{2}{|c|}{ Alumno } & \multirow{2}{*}{\begin{tabular}{|l|} 
Egresado \\
Elegidos \\
\end{tabular}} & \multirow{2}{*}{\begin{tabular}{|c|} 
Patronato \\
Elegidos \\
\end{tabular}} & \multirow{2}{*}{\begin{tabular}{|c|} 
Autoridad \\
Elegidos \\
\end{tabular}} & \multirow{2}{*}{\begin{tabular}{|c|} 
Total \\
Consejc \\
\end{tabular}} \\
\hline & Candidatos & Elegidos & Candidatos & Elegidos & Candidatos & s Elegidos & & & & \\
\hline \multicolumn{11}{|c|}{ Oscar Russo } \\
\hline 1999 & 16 & 8 & 2 & 1 & 16 & 8 & 1 & 1 & 12 & 31 \\
\hline 2000 & 13 & 10 & 2 & 1 & 23 & 10 & 1 & 1 & 12 & 35 \\
\hline 2001 & 15 & 12 & 2 & 1 & 24 & 12 & 1 & 1 & 11 & 38 \\
\hline 2002 & 16 & 13 & 2 & 1 & 26 & 13 & 1 & 1 & 11 & 40 \\
\hline 2003 & 17 & 14 & 2 & 1 & 28 & 14 & 1 & 1 & 11 & 42 \\
\hline \multicolumn{11}{|c|}{ Gonzalo Rodríguez } \\
\hline 2004 & 30 & 15 & 2 & 1 & 25 & 15 & 1 & 1 & 11 & 44 \\
\hline 2005 & 25 & 15 & 2 & 1 & 30 & 15 & 1 & 1 & 12 & 45 \\
\hline 2006 & 21 & 15 & 2 & 1 & 30 & 15 & 1 & 1 & 12 & 45 \\
\hline 2007 & 23 & 14 & 2 & 1 & 28 & 14 & 1 & 1 & 12 & 43 \\
\hline 2008 & 22 & 15 & 2 & 1 & 30 & 15 & 1 & 1 & 12 & 45 \\
\hline 2009 & 18 & 15 & 2 & 1 & 29 & 15 & 1 & 1 & 12 & 45 \\
\hline 2010 & 21 & 17 & 2 & 1 & 26 & 17 & 1 & 1 & 12 & 49 \\
\hline 2011 & 29 & 17 & 2 & 1 & 27 & 17 & 1 & 1 & 12 & 49 \\
\hline \multicolumn{11}{|c|}{ Roberto Cruz } \\
\hline 2012 & 23 & 17 & 2 & 1 & 31 & 17 & 1 & 1 & 12 & 49 \\
\hline 2013 & 27 & 16 & 4 & 1 & 20 & 16 & 1 & 1 & 12 & 47 \\
\hline 2014 & 25 & 15 & 5 & 1 & 31 & 15 & 1 & 1 & 12 & 45 \\
\hline 2015 & 23 & 15 & 2 & 1 & 30 & 15 & 1 & 1 & 12 & 45 \\
\hline \multicolumn{11}{|c|}{ Javier Vales } \\
\hline 2016 & 21 & 16 & 2 & 1 & 28 & 16 & 1 & 1 & 12 & 47 \\
\hline 2017 & 10 & 10 & 2 & 1 & 22 & 16 & 1 & 1 & 12 & 41 \\
\hline 2018 & 23 & 16 & 2 & 1 & 39 & 16 & 1 & 1 & 12 & 47 \\
\hline
\end{tabular}

Fuente: elaboración propia con información de actas del Consejo Directivo, 1999-2018. 
formaban mayoría respecto al sector de representación de la autoridad en el Consejo. Aun así, se observa que no hacen coalición ni colocan agenda sino hasta 2007, por lo cual es evidente que integrar mayoría no es suficiente para la colocación de agenda, sino que se requieren condiciones adicionales.

Esas condiciones que permiten la colocación de agenda en el ITSON son tanto ambientales ${ }^{3}$ como internas. En lo ambiental, un acontecimiento resulta definitorio: la modificación del artículo 15 de la ley orgánica en 2003 que establece un periodo finito de ejercicio del poder. En lo interno, resaltan dos factores clave. El primero de ellos fue el cambio político, concebido por Colomer (2000, p. 25-27) como el paso de un gobierno autoritario o dictatorial a uno democrático a través de un gobierno de transición entre estos dos.

La administración universitaria de Russo Vogel tuvo rasgos autoritarios, por ejemplo, su oposición a la conformación de un sindicato académico en 1989 y despido de sus principales impulsores y simpatizantes; y también presenta rasgos dictatoriales conforme a los conceptos de Sartori (1994) y Bobbio (1998) al posicionarse como principal figura de autoridad por encima del Consejo Directivo. Durante este periodo no hubo condiciones para colocar agenda por agentes diferentes a la autoridad.

Ésa es la etapa autoritaria [...] cuando quiere surgir la figura sindical en la forma de una asociación, y en cuanto surge son corridos de la institución; el comité directivo del sindicato es corrido. No había violado ninguna ley ni nada, al contrario, estaba haciendo uso de sus derechos; es corrido; toman posesión los suplentes y son corridos [...]. Ésa es la etapa a que yo me refiero, donde era muy difícil disentir de la autoridad porque había una consecuencia muy, muy, muy grave. (Informante 12)

Los dos periodos de Gonzalo Rodríguez en la rectoría tuvieron un carácter autoritario liberalizado, si utilizamos la conceptualización de Colomer (2000), al ser designado en un proceso no democrático similar a su antecesor, pero la gran diferencia fue que hubo mayor disposición a procesos negociados de transición.

El segundo factor clave en lo interno es el rechazo de los académicos al modelo de gestión institucional y al lenguaje organizacional ${ }^{4}$ no isomorfo instaurados durante la administración de Gonzalo Rodríguez que impactaba en las rutinas $^{5}$ académicas, al intentar orientarlos a la generación de negocios y al desarrollo regional en detrimento de las funciones tradicionales de docencia, investigación y extensión, lo que no fue bien recibido por los académicos.

3 El nuevo institucionalismo sociológico supone que el cambio sucede por causa de fuerzas exógenas (nuevos marcos interpretativos, evolución de políticas o leyes), por adaptación de las instituciones al medio ambiente (Powell y DiMaggio, 1999).

4 El vocabulario isomorfo permite exponer razonamientos y explicaciones prudentes, legítimas y racionales; las organizaciones que incorporan vocabularios legitimados suponen estar orientadas a propósitos definidos y ordenados de manera colectiva (Meyer y Rowan, 1999, p. 89).

5 as rutinas son patrones de acción conforme a lo que está fijado que debe hacerse, dirigen el comportamiento presente y futuro hacia lo legitimado (March y Olsen, 1997). 
¡Oye, eran proyectos como empresariales! O sea, echar a andar, como palanca de desarrollo económico [...] Estábamos haciendo actividades que no estaban en las funciones de una universidad y se estaban destinando dineros para allá. (Informante 5)

En estas condiciones de gobierno es posible la colocación de agenda por agentes alternos a la autoridad institucional; por lo tanto, la constitución del académico como agente de poder y su consiguiente capacidad de colocación de agenda no es algo que suceda en automático, sino que requiere un mínimo de factores ambientales e institucionales, de mantener la acción, participación y generación de coaliciones ganadoras para tener las condiciones necesarias para continuar explotando las ambigüedades en las reglas y seguir produciendo cambios institucionales.

Tipo de agenda colocada

La agenda colocada por los académicos no tuvo lugar por una acción exclusiva de ellos, sino que sucedió en coalición o alianza con alumnos y administrativos en el Consejo.

Lo que hicimos fue platicar con los maestros en aquel momento representantes; tenían sus propias necesidades y decidimos apoyarlos en algunas peticiones que ellos tenían y pedirles el apoyo [...]. En lo que a mí me tocó vivir, la única manera en que se dio la mayoría [...] fue cuando se unieron los alumnos y maestros. (Informante 14).

La tabla 4 muestra que la agenda colocada por los académicos cubre todas las áreas institucionales (normativa, académica, política, de gobierno, financiera y organizacional ${ }^{6}$ ), lo que denota su amplia capacidad de agencia al hacerse de poder suficiente para disputar todos los recursos institucionales y producir cambios en todas las áreas.

Los representantes de los académicos en el Consejo en el periodo 2007-2018 tuvieron condiciones de fuertes posibilidades de veto y de baja discrecionalidad en las reglas durante este escenario institucional. Produjeron cambios menores pero constantes que a largo plazo resultaron ser significativos (estratificación). Este tipo de cambio, de acuerdo con la TCIG, tiene lugar cuando los retadores institucionales no tienen la capacidad de cambiar las reglas originales y optan por trabajar dentro del sistema agregando nuevas reglas sobre las antiguas (agentes subversivos). Los defensores del sistema no pudieron impedir la introducción de modificaciones y cada nuevo elemento introdujo pequeños cambios que, acumulados, produjeron un gran cambio a largo plazo.

6 Se clasificaron los acuerdos de Consejo de la siguiente forma, en términos generales. Normativos: los acuerdos relativos a creación, modificación, interpretación o derogación de reglamentos o lineamientos institucionales. Académicos: versan sobre ingreso y trayectoria de académicos y alumnos y sobre programas educativos. Política y gobierno: tratan de acuerdos de relación con otros poderes y análisis de decisiones de poder institucional. Financiera: se refiere al ingreso, ejercicio y rendición de cuentas de recursos económicos. Organizacional: alude a estructura, filosofía y dependencias institucionales. 


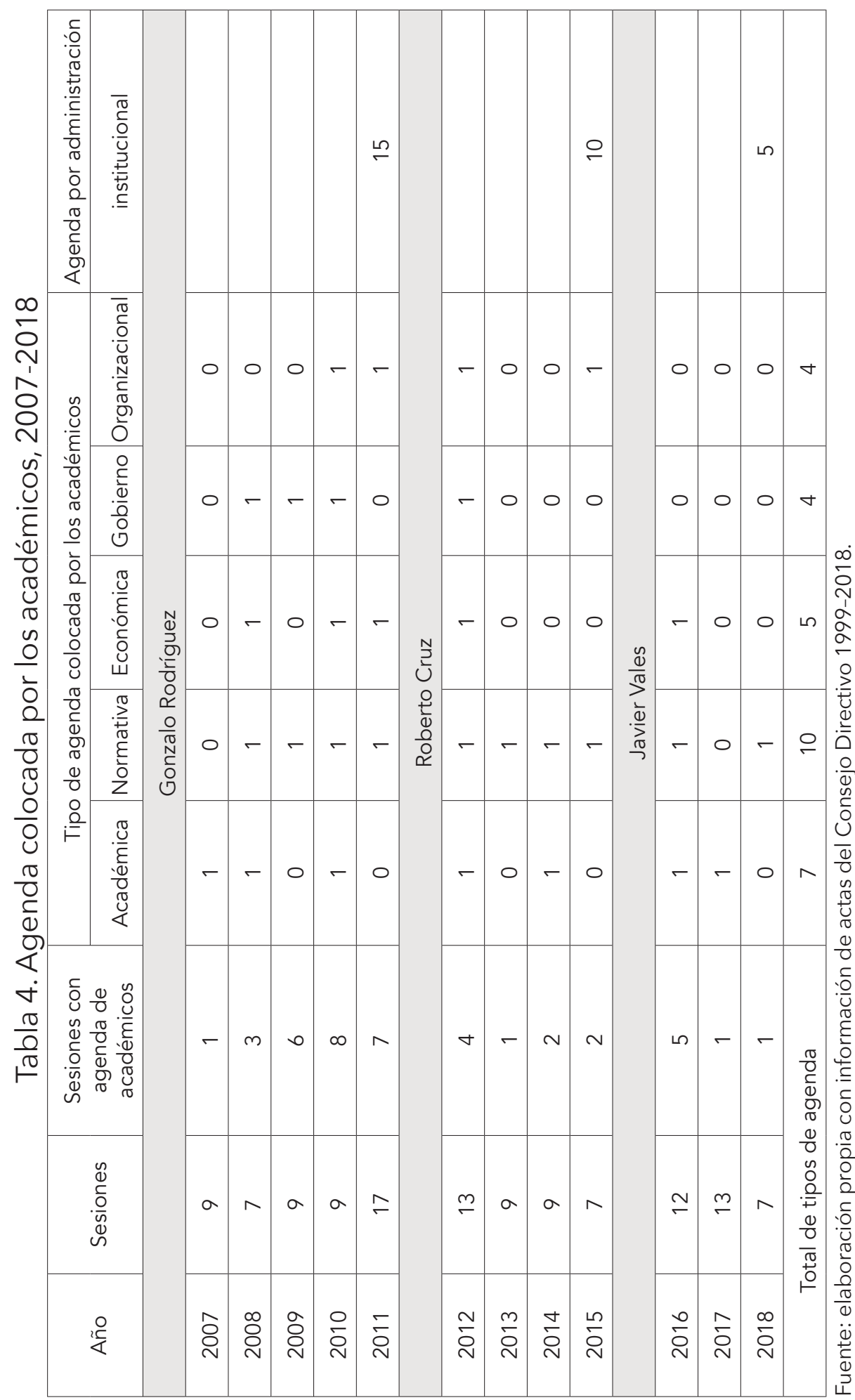


Cambios institucionales producidos por los académicos

Los académicos del ITSON produjeron cambios en distintas dimensiones institucionales. el principal de ellos fue completar el cambio político. Si la modificación del artículo 15 de la ley orgánica por parte del Congreso local permitió el paso de un gobierno autoritario a uno autoritario liberalizado, su iniciativa de modificación del proceso para la designación de rector produjo el arribo de un gobierno democrático. Para lograrlo, explotaron las ambigüedades de la normatividad institucional, como se explica en los criterios de elaboración del reglamento del proceso para la designación de rector del Instituto Tecnológico de Sonora (RPDR) aprobado en abril de 2011.

Del análisis de la normatividad vigente, se observó que el Artículo 9 de la Ley Orgánica en su Fracción I, no define las reglas para designar al Rector, solamente da al Consejo Directivo la atribución para su nombramiento. El Artículo 26 del Reglamento General de la Ley Orgánica, hace referencia a un procedimiento de designación de Rector en términos generales, por lo que se consideró necesario desarrollarlo en un reglamento distinto. (ITSON, 2011, p. 6)

Este reglamento provocó un cambio radical en el acceso a la Rectoría: la máxima autoridad pasó de ser designada por voto a mano alzada por los miembros del Consejo a designación por auscultación secreta a todos los miembros de la comunidad universitaria (académicos, alumnos, no académicos, autoridades, egresados y patronos) y proporcional a su representación en el Consejo. Así se explica el triunfo de Roberto Cruz en la sucesión de rectoría en 2012.

Ahí se aplicó ahora sí, por primera vez, ese reglamento nuevo para la designación del rector en el que se estipula que van a votar los alumnos, que van a votar los académicos, que van a votar egresados; para tener una idea de qué piensan los egresados, el patronato [...] y directivos. (Informante 5)

Este cambio fue particularmente trascendente, dado que sujetó el gobierno de la universidad a la voluntad de la comunidad universitaria, en la que tienen un mayor peso los académicos y los alumnos. Ligado a ello, también se efectuó rotación en los puestos directivos al limitar la permanencia de los funcionarios a un máximo de ocho años, con ratificación a los cuatro años, con lo que una vieja élite fue relevada de la administración universitaria.

El cambio político ha permitido que el ITSON ya no sea una institución en la que el rector tenga asegurada la reelección y el traspaso de poder delegado en un sucesor, sino que este privilegio tiene que dirimirse en un proceso democrático y abierto. En la actualidad existe un reemplazo periódico de las personas que ejercen funciones de autoridad.

Hoy día vemos con mucha normalidad ese tránsito, esa idea de que hoy puedes ser profesor y mañana puedes ser director o puedes ser jefe, 
o sea, no requieres la relación para poder tener esa aspiración, ¿sí me explico? O sea, se vuelve como más, esa capa se vuelve menos difusa, es mucho más permeable. (Informante 4)

Los cambios políticos en el ITSON se sustentaron en cambios normativos cuando los académicos explotaron las ambigüedades en la ley orgánica y su reglamento general. Tuvieron la capacidad de promover enmiendas, revisiones, adiciones y producción de nueva normatividad que, acumulada, produjo un cambio por estratificación tal como lo señala la TCIG.

No sólo se elaboró el reglamento para designación de rector, también se reglamentó el funcionamiento del Consejo Directivo para hacer su operación menos discrecional y subordinada. Se crearon comisiones necesarias y se pusieron en operación otras que existían sólo en papel. También se modificó la operación de la Comisión Académica Permanente dándole paridad en su conformación entre directivos y académicos, más interés institucional, al tratarse del órgano colegiado de ingreso y promoción de personal académico.

Respecto al manejo de recursos financieros, se dieron los siguientes cambios. Se dispuso la operación formal de la comisión de auditoría (existía de forma nominal) y la creación de la comisión de fiscalización y control para supervisar el gasto institucional. Se sometió a la autoridad a la rendición de informes financieros trimestrales (contemplado en la normatividad, pero sin cumplimiento previo). Se puso tope a las pensiones y a las jubilaciones haciéndolas sostenibles y se sometió a aprobación del Consejo el ejercicio del recurso de fideicomisos institucionales. Con estas medidas, el ejercicio del recurso financiero ya no es exclusivo de la autoridad y permite una labor de supervisión rigurosa que obliga a la administración universitaria a un manejo mucho más cuidadoso y menos discrecional de las finanzas institucionales.

Los cambios académicos tuvieron doble efecto: reducción de la discrecionalidad y priorización de méritos en el ingreso, promoción y reconocimiento de los profesores. Se acuerda paridad de académicos y autoridades en el órgano responsable del ingreso y promoción académica, se consensa la composición de jurados calificadores para ingreso en base a méritos y se reconoce como personal académico a técnicos académicos e instructores en el reglamento correspondiente.

Éstos y otros cambios han sido gracias al trabajo de los representantes académicos en el Consejo Directivo, quienes, en coalición con los representantes de los alumnos y el representante de los trabajadores no académicos, han sido capaces de establecer agenda y desplazar el statu quo del ITSON.

\section{Conclusiones}

Lo novedoso que el caso del ITSON aporta al estudio de cambio institucional en las universidades públicas es el papel de los académicos dentro del mismo. Si investigaciones previas advertían de su pérdida de poder e influencia en el devenir de la universidad, este estudio, con sustento en la TCIG, demuestra que 
los académicos han producido un cambio institucional al incidir en las normas en forma de enmiendas, revisiones o adiciones a lo largo de diez años, lo que ha permitido una recreación de la universidad en todas las dimensiones más acorde a sus intereses.

Un cambio en las reglas de acceso al poder propició el cambio político. El ITSON, con un gobierno de rasgos autoritarios y dictatoriales, en sus primeros 27 años de autonomía institucional ha caducado luego de un periodo de transición entre los años 2007 y 2011, y a partir del año 2012 ha emergido y se ha consolidado una forma de gobierno democrática, en particular en la forma de designación de rector y en la integración de su consejo de gobierno como principales figuras de autoridad unipersonal y colegiada.

Los ajustes normativos impulsados por los académicos produjeron también un cambio organizacional para hacerlo más trasparente y meritocrático. En este sentido, la discrecionalidad en la incorporación y promoción del personal académico es acotada al lograrse paridad académico-directiva en el órgano responsable, reforzando los criterios académico-meritocráticos. El manejo de los recursos financieros se transparenta en atención a requerimientos contextuales e institucionales, lo cual permite un seguimiento más puntual del ejercicio de los subsidios federales, estatales y los recursos propios. La creación de estímulos internos a la docencia, la investigación y al desempeño burocrático de los trabajadores no académicos son también evidencia de un cambio organizacional favorable a la base trabajadora.

La adición y la modificación normativa sobre las reglas institucionales existentes produjeron también un cambio académico. La orientación no isomorfa que caracterizó el periodo de transición institucional y que era contraria a la pericia académica, se abandonó en favor de una orientación institucional isomorfa a las políticas y más alineada a las capacidades y vocación académica.

El ITSON se ha trasformado. Ya no es la institución autoritaria, de normatividad escasa, discrecional y ajena a las políticas públicas de educación superior. En la última década ha experimentado un cambio institucional para ser democrática con apego a las normas, meritocrática y con calidad reconocida conforme a los estándares establecidos a nivel nacional. Esto es resultado de la constitución de los académicos en agentes de cambio institucional. Ellos aprovecharon las condiciones ambientales e institucionales que generaron la acción del Congreso local y la orientación no isomorfa de una administración institucional.

El cambio en el ITSON no es un proceso acabado. Requiere la movilización constante de recursos para la permanencia del estado institucional alcanzado por parte de los agentes interesados. Es importante continuar observando este proceso.

\section{Referencias}

Acosta Silva, A. (2000). Estado, políticas y universidades en un periodo de transición. México: UdeG y Fondo de Cultura Económica (FCE). 
Acosta Silva, A. (2002). Las dimensiones sociológicas y políticas del cambio institucional. En Autor (coord.), Ensayos sobre cambio institucional (pp. 1742). Zapopan: UdeG.

Almeida López, M. (2012). La Universidad de Guadalajara (México), la descentralización y el desarrollo regional. Tesis de doctorado, Oviedo: Universidad de Oviedo. Recuperada de https://www.educacion.gob.es/teseo/imprimirFicheroTesis.do?idFichero=509v\%2BvR4K\%2F4\%3D

Altbach, P. (1991). Los modos de desarrollo de la enseñanza superior: hacia el año 2000. Perspectivas, 21(2), 205-220.

Álvarez Mendiola, G., y Vries, W. de. (2014). Un modelo agotado de relación entre el Estado y las instituciones de educación superior. En H. Muñoz García (coord.), La universidad pública en México. Análisis, reflexiones y perspectivas (pp. 37-54). México: Universidad Nacional Autónoma de México (UNAM).

Arias Guzmán, A. A., Ceja Mendoza, A. P., Ramos Carrillo, E. M., y Ríos Colín, Y. (2011). Gobernabilidad y cambio institucional en la Universidad Autónoma de Nayarit durante el periodo 2000-2008. Revista de la Educación Superior, 40(157), 129-148.

Bobbio, N. (1998). Diccionario de política. Buenos Aires: Siglo XXI.

Brunner, J. J. (2014). La idea de la universidad pública en América Latina: narraciones en escenarios divergentes. Educación XX1, 17(2), 17-34. Recuperado de https://www.redalyc.org/articulo.oa?id=706/70630580018

Casanova Cardiel, H. (2015). Universidad y Estado. Del pensamiento del siglo XIX a las reflexiones de la primera mitad del siglo XX. Universidades (65), 49-57. Recuperado de https: / / www.redalyc.org/pdf/373/37341213005.pdf

Casar, M., y Maldonado, C. (2008). Formación de agenda y procesos de toma de decisiones: una aproximación desde la ciencia política. México: Centro de Investigación y Docencia Económicas.

Colomer, J. M. (2000). Cambio Político. En L. Baca Olamendi, J. Bokser-Liwerant, F. Castañeda, I. H. Cisneros, y G. Pérez Fernández del Castillo (comps.), Léxico de la política (pp. 23-28). México: Facultad Latinoamericana de Ciencias Sociales y FCE.

Comas Rodríguez, O., Fresán Orozco, M., Buendía Espinosa, A., y Gómez Morales, I. (2014). El PIFI en las universidades públicas: de la decisión racional a la legitimidad institucional. Revista de la Educación Superior, 169(1), 47-67. Recuperado de https: / / www.redalyc.org/articulo.oa?id=60430753004

Congreso del Estado de Sonora. (2 de octubre de 1976). Ley orgánica del Instituto Tecnológico de Sonora. Ley núm. 2. Recuperado de https://www. ITSON.mx/universidad/Legislacin/LEY\%200RG\%C3\%81NICA\%20DEL\%20INSTITUTO\%20TECNOL\%C3\%93GICO\%20DE\%20SONORA.pdf

Congreso del Estado de Sonora. (22 de octubre de 2003). Ley orgánica del Instituto Tecnológico de Sonora. Decreto núm. 44. Recuperado de https:/ /www. ITSON.mx/universidad/Legislacin/LEY\%200RG\%C3\%81NICA\%20DEL\%20INSTITUTO\%20TECNOL\%C3\%93GICO\%20DE\%20SONORA.pdf 
Cortés Vargas, D. (21 de marzo de 2009). El cambio institucional universitario y sus corrientes teóricas de interpretación. Recuperado de https://www. academia.edu/4881473/El_cambio_institucional_universitario_y_sus_corrientes_te\%C3\%B3ricas_de_interpretaci\%C3\%B3n

DiMaggio, P., y Powell, W. (1999). Retorno a la jaula de hierro: el isomorfismo institucional en los campos organizacionales. En W. Powell y P. DiMaggio, El nuevo institucionalismo en el análisis organizacional (pp. 105-125). México: FCE.

Durand Villalobos, J. P. (2006). Poder, gobernabilidad y cambio institucional en la Universidad de Sonora 1991-2001. México: Asociación Nacional de Universidades e Instituciones de Educación Superior (ANUIES).

Fuentes Molinar, O. (1991). Las cuestiones críticas de la educación superior. Universidad Futura, 3(8-9), 5-12.

Galaz Fontes, J. F., y Viloria Hernández, E. (2004). La toma de decisiones en una universidad pública estatal desde la perspectiva de sus académicos. RMIE, (22)9, 637-663. Recuperado de https://www.researchgate.net/publication/28078241_La_toma_de_decisiones_en_una_universidad_publica_estatal_desde_la_perspectiva_de_sus_academicos

Galaz Fontes, J. F., y Viloria Hernández, E. (2014). Académicos y gobierno institucional en las universidades públicas mexicanas: situación y perspectivas. En H. Muñoz García (coord.), La universidad pública en México (pp. 215236). México: UNAM y Miguel Ángel Porrúa.

Galaz-Fontes, J. F., y Gil-Antón, M. (2013). The impact of merit-pay systems on the work and attitudes of Mexican faculty. Higher Education, 66(3), 357-374. doi: 10.1007/s10734-013-9610-3

Giddens, A. (2006). La constitución de la sociedad. Bases para la teoría de la estructuración. Buenos Aires: Amorrortu.

Gil Antón, M. (2013). La monetarización de la profesión académica en México: un cuarto de siglo de transferencias monetarias condicionadas. Espacios en Blanco. Revista de Educación (23), 157-186. Recuperado de https://www. redalyc.org / articulo.oa?id $=384539805008$

Gómez, A. (2015). Enfoques recientes para el análisis del cambio institucional. La teoría distribucional del cambio gradual. Política y gobierno, 22(2), 391415.

Ibarra Colado, E., y Porter Galetar, L. (2007). El debate sobre la evaluación: del homo academicus al homo economicus. REencuentro. Análisis de Problemas Universitarios (48), 34-39. Recuperado de https://www.redalyc.org/articulo. oa?id=34004805

Instituto Tecnológico de Sonora (ITSON). (2 de octubre de 2019). Historia. Recuperado de https://www.ITSON.mx/Universidad/Paginas/historia.aspx

Instituto Tecnológico de Sonora (ITSON). (21 de marzo de 2018). Agenda de información estratégica 2001-2017. Ciudad Obregón, Sonora, México.

Instituto Tecnológico de Sonora (ITSON). (junio de 2011). ITSON y su gente. Reglamento del proceso para la designación de rector del Instituto Tecnológico de Sonora (núm. 550). Recuperado de https://www.ITSON.mx/publicaciones/ITSONysugente/Documents/ITSONysugente-550.pdf 
Kandel, V. (2010). Gobierno universitario y participación estudiantil. Consideraciones sobre el cogobierno y la democracia en la universidad pública. Propuesta Educativa, 2(34), 97-103. Recuperado de https://www.redalyc.org/ articulo.oa?id=403041705010

Kent Serna, R. (2009). Las políticas de educación superior en México durante la modernización. México: ANUIES.

López Zárate, R. (2012). ¿Es el programa integral de fortalecimiento institucional (PIFI) una moda? Revista de la Educación Superior, 41(163), 91-114.

Mahoney, J., y Thelen, K. (2010). Explaining Institutional Change: Ambiguity, Agency and Power. Nueva York: Cambridge University Press.

March, J. G., y Olsen, J. P. (1997). El redescubrimiento de las instituciones. La base organizativa de la política. México: FCE.

Mendoza Rojas, J. (1992). El proyecto de modernización universitaria: continuidad e innovaciones. Revista de la Educación Superior, 84, 1-18. Recuperado de http://publicaciones.anuies.mx/pdfs/revista/Revista84_S1A1ES.pdf

Meyer, J., y Rowan, B. (1999). Organizaciones institucionalizadas: la estructura formal como mito y ceremonia. En W. Powell, y P. DiMaggio, El nuevo institucionalismo en el análisis organizacional (pp. 79-103). México: FCE.

Ordorika Sacristán, I. (2004). El mercado en la academia. En Autor (coord.), La academia en jaque. Perspectivas políticas sobre la evaluación de la educación superior en México (pp. 35-74). México: UNAM y Porrúa.

Ornelas, C. (1998). De la crisis a la reconstrucción. El cambio institucional en la Benemérita Universidad Autónoma de Puebla. México: ANUIES.

Pérez Muñoz, S., y Castaño Calle, R. (2016). Funciones de la universidad en el siglo XXI: humanística, básica e integral. Revista Electrónica Interuniversitaria de Formación de Profesorado, 19(1), 191-200. Recuperado de https: / / www. redalyc.org/articulo.oa?id=217043419015

Porter Galetar, L. (2004). La planeación de la autoridad. La planeación de la libertad. Inconsistencias e incompatibilidades del Programa Integral de Fortalecimiento Institucional (PIFI). Revista Mexicana de Investigación Educativa, 9(22), 585-615. Recuperado de https: / / www.redalyc.org / pdf/140/14002203. pdf

Powell, W., y DiMaggio J, P. (1999). El nuevo institucionalismo en el análisis organizacional. México: FCE.

Przeworski, A. (2005). Qué esperar de la democracia. Límites y posibilidades del autogobierno. Buenos Aires: Siglo XXI.

Rodríguez Gómez, R. (2009). La coordinación de sistemas universitarios en la transición federalista. Panorama internacional y el caso de México. En M. Mollis (comp.), Memorias de la universidad: otras perspectivas para una nueva Ley de Educación Superior (pp. 2-30). Buenos Aires: Consejo Latinoamericano de Ciencias Sociales.

Rodríguez Gómez, R. (2015). La ANUIES y la confección de las políticas de educación superior en México 1970-2000. En G. Álvarez Mendiola (coord.), La ANUIES y la construcción de políticas de educación superior 1950-2015 (pp. 73-105). México: ANUIES. 
Rodríguez Gómez, R., y Casanova, H. (2005). Modernización incierta. Un balance de las políticas de educación superior en México. Perfiles Educativos, 107, 40-56. Recuperado de https: / / www.redalyc.org/pdf/132/13210703.pdf

Rueda Beltrán, M. , y Diego Correa, M. de. (2012). Las políticas de evaluación de los académicos universitarios. Perfiles Educativos, 34, 93-106. Recuperado de https: / / www.redalyc.org/articulo.oa?id=13229959009

Sartori, G. (1994). ¿Qué es la democracia? Bogotá: Altamir ediciones.

Silva Montes, C. y Castro Valles, A. (2014) Los cuerpos académicos, recursos y colegialidad forzada. Archivos Analíticos de Políticas Educativas, 22(68).

Suárez Zozaya, M. H., y Muñoz García, H. (2004). Ruptura de la institucionalidad universitaria. En I. Ordorika Sacristán (coord.), La academia en jaque. Perspectivas políticas sobre la evaluación de la educación superior en México (pp. 25-33). México: Miguel Ángel Porrúa.

Valenti Nigrini, G., y Castillo Alemán, G. del. (1997). Interés público y educación superior: un enfoque de política pública. En A. Mungaray Lagarda, y G. Valenti Nigrini (coords.), Políticas públicas y educación superior (pp. 89117). México: ANUIES.

Vargas Becerril, H., Aguilera Guerrero, A. T., y Anaya Mexía, S. (2005). ITSON 50 años 1955-2005. Ciudad Obregón: ITSON.

Vergara, R. (2010). Introducción. En Autor (comp.), Organización e instituciones (pp. 17-47). México: Siglo XXI.

Vries, W. de, y Álvarez Mendiola, G. (2005). Acerca de las políticas, la política y otras complicaciones en la educación superior mexicana. Revista de la Educación Superior, 134(2), 81-105. 